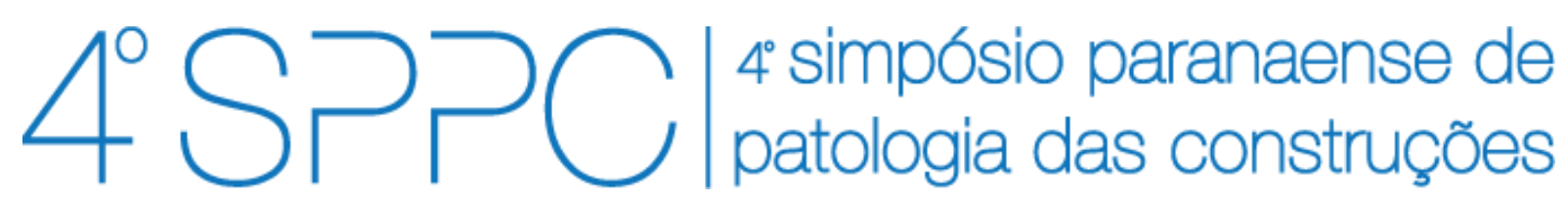

ISSN 2526-7248 artigo n. 4SPPC137, pp. 331-337, 2019

\title{
Revisão histórica sobre a preservação do patrimônio arquitetônico
}

\author{
Klosowski, Bernardo 1; Luso, Eduarda C. P. 2; Medeiros, Arthur ${ }^{3}$ \\ ${ }^{1}$ Estudante de Engenharia Civil e Engenharia da Construção, Universidade \\ Tecnológica Federal do Paraná e Instituto Politécnico de Bragança, \\ klosowskibernardo@gmail.com \\ 2 Engenheira Civil, Instituto Politécnico de Bragança, eduarda@ipb.pt \\ ${ }^{3}$ Engenheiro Civil, Universidade Tecnológica Federal do Paraná, \\ arthur.med@gmail.com
}

Resumo: A interferência antrópica em objetos antigos é permeada de muitas incertezas, mesmo quando pretende-se realizar o restauro, a manutenção e a reabilitação dos mesmos. De acordo com Confúcio, filósofo chinês, o homem que deseja prever o futuro deve primeiro estudar o passado. A partir desta afirmação, este artigo pretende, através de uma revisão histórica, contribuir como alicerce dos conceitos atuais e vindouros da conservação do patrimônio arquitetônico. O estudo inicia-se nas primeiras concepções sobre o tema ainda na Idade Antiga e evolui cronologicamente pela Idade Média, Modernidade, os últimos dois séculos e as perspectivas atuais a respeito do restauro e da preservação de edificações antigas.

Palavras-chave: restauro, conservação, patrimônio histórico, revisão histórica.

Abstract: The anthropic interference in ancient artifacts is permeated with many uncertainties, even when there is an intention to perform the restoration, maintenance and rehabilitation of these objects. According to Confucius, a Chinese philosopher, the man who wishes to foresee the future must firstly study the past. From this statement, this article intends, through a historical revision, to contribute as a base of the current and future concepts of the conservation of the architectural patrimony. The study begins with the earliest conceptions of the theme still in the Old Age and evolves chronologically by the Middle Ages, Modernity, the last two centuries and the current perspectives regarding the restoration and preservation of ancient buildings.

Keywords: restoration, conservation, architectural heritage, historical review. 


\section{Introdução}

Dada a certeza da degradação das construções, seja por efeito antrópico, biológico, atmosférico ou de outra natureza, faz-se necessário pensar a respeito de sua conservação. A Carta de Cracóvia [1] define este conceito como o conjunto de atitudes que uma comunidade toma com o objetivo de perpetuar o patrimônio e os seus monumentos, através do respeito pelo significado de sua identidade e do reconhecimento dos valores que the estão associados.

Por outro lado, o mesmo documento cita a diversidade cultural do mundo contemporâneo e a pluralidade de valores fundamentais, que certamente culminarão em amplas divergências sobre obras de reabilitação e restauro. No momento da escrita deste trabalho, alguns meses após parte da Catedral de NotreDame arder em chamas, observam-se conflitos deste tipo quanto a estratégia a ser adotada em seu restauro.

De acordo com Confúcio, filósofo chinês, o homem que deseja prever o futuro deve antes estudar o passado. De maneira resumida, pretende-se que este artigo sirva como um contributo para a tomada de decisão nesta e em outras situações.

\section{Objetivos}

Pretende-se com este trabalho sistematizar o conhecimento existente a respeito do restauro de edificações antigas. Para isto, propõe-se a revisão histórica das principais concepções a respeito deste tema, partindo da antiguidade e dirigindo-se cronologicamente até os tempos modernos e às percepções atuais.

\section{A Antiguidade e a Idade Média}

Os primeiros registros humanos datam de aproximadamente 4000 A.C, quando houve a invenção da escrita e consequentemente o início da Era Antiga. Neste mesmo período histórico já constam registros da preocupação com a recuperação de artefatos antigos. Contudo, na maioria das vezes não havia a intenção de preservar o registro histórico, mas apenas de reconstituir as funcionalidades ou a estética de peças de uso cotidiano [2-4].

Durante o período greco-romano houve a tentativa de obter a "imortalidade" da matéria, ou seja, manter sempre "vivos" os edifícios. Esta mentalidade acarretou diversas reconstruções radicais, visto que o compromisso era com as formas originais, mas não com a história. Por outro lado, há um relato de que no tempo de Nero um restaurador foi demandado pelo imperador para recompor uma pintura de Vênus, curiosamente a deusa da beleza, que já não tinha mais o aspecto original. Este profissional, já naquela época, teve a consciência de que não tinha as habilidades necessárias para concluir tal trabalho e decidiu que guardaria o afresco original e apresentaria uma cópia ao imperador [4-6]. 


\section{A Modernidade}

O início do reconhecimento histórico das edificações e obras de arte antigas deu-se durante o Renascimento, quando houve uma grande valorização estética das obras clássicas. Ainda que em 1692 tenha sido publicado o documento que é considerado como a primeira legislação a respeito do restauro, a Bula Cum Alman Nostram Urbem, de Pio II, as intervenções desta época são marcadas pela radicalidade dos repintes, muitos deles tendo mudado inclusive o sentido simbólico das obras originais. Datam da mesma época os primeiros inventários das ruínas de Roma e das técnicas de limpeza que foram utilizadas nestas tarefas [5, 7].

No século XVI inicia-se o período Barroco, que foi marcado pela ascensão do colecionismo e pela criação das primeiras galerias de arte da Europa. Apesar de a arte e a arquitetura estarem plenamente reconhecidas, muitas intervenções de restauro foram feitas objetivando apenas a estética das peças. Frequentemente, os retoques eram feitos conforme as preferências dos donos das galerias sem que houvesse a preocupação em manter a originalidade. A limpeza e o restauro do teto da Capela Sistina foram grandes feitos deste tempo [5].

Durante o período do neoclassicismo houve uma concentração de obras de arte e artefatos históricos na Europa, principalmente na Inglaterra, França e Espanha. Em consequência ocorreu o surgimento dos primeiros grandes museus, nomeadamente - Museu Britânico, em Londres, o Museu do Prado, em Madrid e o Museu do Louvre, em Paris. Com a grande demanda das funções de restauro, começou-se a realizar a atribuição destas atividades a profissionais capacitados, que haviam estudado o assunto e sabiam como empregar os conhecimentos de física e química existentes [6, 8].

O grande nome do restauro desta época foi Pietro Edwards, um italiano de origem inglesa que atuava na região de Veneza. Este restaurador tinha o costume de escrever relatórios a respeito das tarefas que realizava bem como dos diagnósticos e causas das degradações encontradas. Pietro estabeleceu normas e critérios a respeito do armazenamento, da intervenção e dos exames das obras de arte, tendo inclusive se preocupado com a reversibilidade das interferências realizadas. Também foi dele o primeiro projeto de criação de uma escola totalmente voltada para o restauro de obras de arte. Considera-se este restaurador como o pioneiro do restauro

científico [5].

Um dos resultados da Revolução Francesa, que marca o fim da Idade Moderna e início da Contemporaneidade, foi a grande quantidade de monumentos, edifícios e demais obras de arte degradadas e vandalizadas. Por consequência, no ano de 1794, o governo francês finalmente regulamenta a atividade de restauro, publicando o documento chamado de Princípio da Conservação dos Monumentos [5, 9]. 
KLOSOWSKI, B.; LUSO, E.C.P.; MEDEIROS, A., REVISÃO HISTÓRICA SOBRE A PRESERVAÇÃO DO PATRIMÔNIO ARQUITETÔNICO. $4^{\circ}$ Simpósio Paranaense de Patologia das Construções (40 SPPC), artigo 4SPPC137, pp. 331 - $337,2019$. DOI: $10.4322 / 2526-7248.055$

\section{O século XIX}

O romantismo do século XIX foi marcado por interpretações antagônicas quando trata-se de restauro: de um lado, o ponto de vista francês, personificado em ViolletLe-Duc e do outro, a perspectiva inglesa cuja grande referência era John Ruskin [10].

Eugène Viollet-Le-Duc foi um arquiteto e historiador francês de ideais polêmicos acerca da restauração de edificações históricas. Segundo ele, o objetivo da modificação seria voltar o edifício ao seu estado de quando novo ou então, prevendo como seria após a sua conclusão. Na perspectiva deste Arquiteto, o restaurador não deveria utilizar conceitos pessoais na reconstrução, mas sim colocar-se na pele do construtor original, baseando-se em documentos, regras de estilo, projetos ou desenhos originais [10].

De forma contraditória, observa-se que Viollet-Le-Duc não seguiu à risca suas recomendações. O Castelo de Pierrefonds, na França, é o exemplo característico de restauro em que este arquiteto adicionou modificações que não constavam nos planos dos construtores iniciais. A obra original data de 1396, quando o Duque de Orleães ordenou que a fortaleza fosse construída como uma fortificação militar. Já em 1617 foi destruído parcialmente pelo Rei Luis XIII, sendo então chamado de "Ruínas Pitorescas" (Figura 1). Em 1857, Napoleão III decide restaurar o edifício e designa Eugène para a função. $O$ resultado (Figura 2) foi um Castelo do período da Idade Média, com interior em estilo romântico, um pavimento a mais em algumas regiões e diversas alterações que atestam o emprego das concepções pessoais do arquiteto [11].

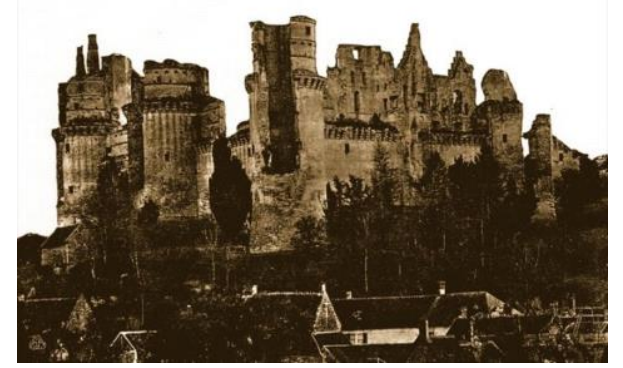

Figura 1: Castelo de Pierrefonds ainda em ruínas. Fonte: Archives Photographiques, Paris ${ }^{1}$.

John Ruskin foi um crítico de arte e sociólogo inglês com ideias antagônicas a Viollet-Le-Duc. Em seu ponto de vista, deve-se respeitar rigorosamente 0 monumento, mesmo que este esteja em estado de ruínas, inaugurando assim 0 movimento anti-restauro. A solução ideal seria realizar a manutenção preventiva de modo com que não fosse necessária a intervenção corretiva. Segundo ele, as

${ }^{1}$ Disponível em <http://www.raybishophistory.co.uk/lawrence-rides-south-andinto-the-middles-ages/a-selection-of-castles-visited-by-lawrence/pierrefonds/>, acesso em Junho de 2018. 
KLOSOWSKI, B.; LUSO, E.C.P.; MEDEIROS, A., REVISÃO HISTÓRICA SOBRE A PRESERVAÇÃO DO PATRIMÔNIO ARQUITETÔNICO. $4^{\circ}$ Simpósio Paranaense de Patologia das Construções (40 SPPC), artigo 4SPPC137, pp. 331 - $337,2019$. DOI: $10.4322 / 2526-7248.055$

intervenções posteriores ao período da obra são "mentiras arquitetônicas" em razão de que as obras do passado deveriam ser mantidas imaculadas $[5,7,12]$.

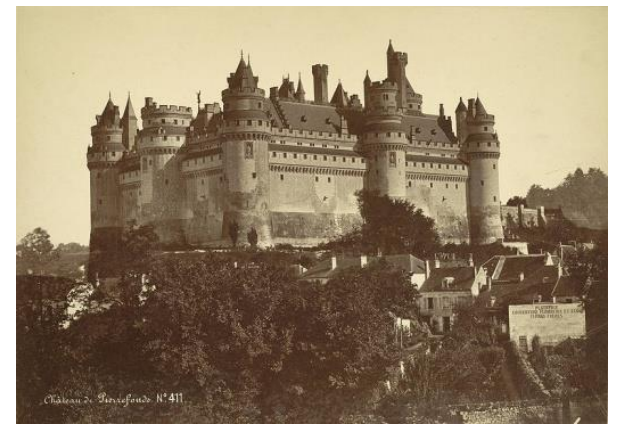

Figura 2: Castelo de Pierrefonds depois do restauro de Viollet-Le-Duc. Fonte: Cornell University Library².

\section{Os séculos $X X$ e XXI}

Já no século XX, Camillo Boito sugere novos conceitos que serviram de base para os critérios atuais de restauro. Este arquiteto, escritor e historiador italiano propõem uma visão intermediaria entre os ideais de Ruskin e Viollet-Le-Duc. De acordo com ele, a manutenção preventiva deveria sempre ser feita, de modo com que as intervenções de restauro só devessem ser feitas quando não houvesse outra opção. Boito também recomenda que deva-se manter o respeito sobre todas as partes do edifício, mesmo que estas tenham sido adicionadas depois do período da construção, por outro lado, condena que sejam feitos restauros estilísticos visto que estes "falsificam o monumento" [7, 11].

Camillo ainda sugeriu algumas diretrizes que são aceitas até hoje: realizar apenas as intervenções necessárias e identificá-las muito bem; deixar evidentes quais foram as partes e os materiais adicionados e caso hajam partes eliminadas, expô-las junto com registros e fotografias da obra em um local público. Boito ainda sugeriu que no próprio monumento fosse gravada a data e a descrição das intervenções [11].

Devido às diversas correntes de pensamento e teorias a respeito do restauro, estabeleceu-se a necessidade de criar regras internacionais aceitas por todos a respeito deste tema. A Carta de Atenas, escrita em 1931, veio para dar início a resolução deste problema. Inspirada em grande parte pelos ideais de Camillo Boito, ela criou um ponto de referência para a tutela e manutenção dos monumentos arquitetônicos e obras de arte da Europa. Entre as suas ideias principais estava a importância da manutenção preventiva, da reutilização do edifício, da valorização da envolvente, da possibilidade de uso de materiais modernos e também da conscientização das pessoas. Por influência, outros regulamentos e cartas de restauro foram publicados posteriormente em diversos países da Europa $[3,11]$.

Após o final da Segunda Guerra Mundial em 1945, diversas cidades, monumentos arquitetônicos e obras de arte da Europa estavam em ruínas, em vista disso, o

2 Disponível em <https://digital.library.cornell.edu/catalog/ss:3875007>, acesso em Junho de 2018. 
panorama do restauro precisou ser revisto. O líder desta remodelagem foi Cesare Brandi, um italiano, que além de fundador e diretor do Istituto Centrale di Restauro, também era crítico de história e formado em Direito [3, 9].

Brandi foi o inaugurador da corrente conhecida por Restauro Crítico. Devido às grandes destruições provocadas pelos incêndios e bombardeiros na década de 40, o valor histórico de um monumento deveria ser superado pelo seu valor estético e artístico [10]. Ou seja, seria justificável realizar intervenções mais intensas do que as descritas na Carta de Atenas em função de reestabelecer a unidade potencial da obra de arte [11, 13].

Desta forma, cada edificação deveria ser restaurada de uma maneira específica, porém, sem apagar as marcas da passagem do tempo, cometer ilegitimidades artísticas ou históricas ou impossibilitar intervenções futuras. Em 1963, Cesare escreveu o livro chamado Teoria do Restauro, que foi uma das maiores bases para a Carta de Veneza, publicada em 1964. No mesmo período, destaca-se também a criação do ICOMOS (Conselho Internacional de Monumentos e Sítios), uma organização não governamental cuja missão é promover a conservação, proteção e valorização de centros urbanos e monumentos [3, 13].

No final do século XX, durante a Conferência Internacional Sobre Conservação, foi publicada a Carta de Cracóvia [1]. Este documento foi formulado com o objetivo de adequar as premissas já contidas na Carta de Veneza às peculiaridades previstas para o século XXI. Foram englobados conceitos como a evolução tecnológica das técnicas de restauro, a noção da preservação de paisagens, do patrimônio arqueológico e do ambiente e as limitações econômicas que permeiam estas obras [11].

\section{Conclusão}

O olhar ao passado do restauro e da preservação do patrimônio histórico permite entender que não existem dogmas incontestáveis nesta temática. Pelo contrário, as considerações sobre 0 que é correto transformam-se continuamente e provavelmente permanecerão se transformando no futuro. Cabe aos profissionais desta área terem a compreensão para encarar cada situação de forma única e multidisciplinar, de forma a não apenas evitar danos irreparáveis no patrimônio, mas também conservar sua autenticidade e significado cultural.

Além das dúvidas éticas e morais, ainda é preciso garantir a viabilidade financeira deste tipo de intervenção, que frequentemente apresenta custos tão elevados que superam aqueles da construção de uma edificação nova equivalente. Primeiramente, entende-se que estas edificações devem se manter úteis e habitadas, mesmo que precisem ter seus espaços utilizados para fins diversos dos originais, como universidades, teatros ou museus. Ainda, assume-se a possibilidade da utilização do turismo, uma das indústrias que mais cresce neste século e é frequentemente impulsionada pelas edificações históricas, para financiar os processos de preservação. 
Compreende-se que as falhas cometidas no passado fizeram parte do processo evolutivo desta ciência. Espera-se que a elaboração dos projetos de reabilitação e restauro a serem realizados no futuro sejam feitos por aqueles que dominam os critérios técnicos apropriados e também a sensibilidade e respeito pela história e pela cultura.

\section{Referências}

[1] AA.VV. (2000). Krakow Charter: principles for conservation and restoration of built heritage.

[2] Choay, F. (2007). Alegoría del patrimonio, Cuatro Cuadernos. Apuntes de Arquitectura y Patrimonio.

[3] Tavares, M. L. (2009). A conservação e o restauro de revestimentos exteriores de edifícios antigos: 'Uma metodologia de estudo e reparação', Preservation.

[4] Miguel, A. M. M.; Mozo, A. G. (2004). La conservación y la restauración en el siglo XX, Editorial Tecnos.

[5] Justicia, M. J. M.; Martínez, D. S.-M.; Martínez, L. S.-M. (2008). Historia y Teoría de La Conservación y Restauración Artística, Tecnos.

[6] Elias, I. B. (2010). Conservação e restauro de obras com valor de contemporaneidade.

[7] Rivera, J. (1997). Restauración arquitectónica desde los orígenes hasta nuestros días, Teoria e Historia de La Resturacíon. Tomo 1: Máster de Restauración e Rehabilitación Del PAtrimonio., Madrid.

[8] Caldeira, C. C. (2005). Conservação Preventiva: histórico, Revista CPC.

[9] Jokilehto, J. (2006). Considerations on authenticity and integrity in World Heritage context, City \& Time.

[10] Aguiar, J. (1999). Estudos cromáticos nas intervenções de conservação em centros históricos, Tese de DoutoradoUniversidade de Évora.

[11] Luso, E.; Lourenço, P. B. (2004). Breve história da teoria da conservação e do restauro, Revista Engenharia Civil Da Universidade Do Minho.

[12] Henriques, F. (1991). A Conservação Do Património Histórico Edificado, LNEC, Lisboa.

[13] Brandi, C. (1963). Teorial Del Restauro, Ed. di storia e letteratura. 